\title{
Busman's holiday
}

I lay in the neurosurgical ward recovering from insertion of my ventriculo-peritoneal shunt and listening to the incessant talk of my neighbour. He had decided that as we shared a battle-front we were the best of friends. Much disclosure on his side called for me to reveal my way of life - as a doctor - to which he retorted "Oh, so it's a busman's holiday"!

I developed hydrocephalus at the age of 53 as a consequence of aqueduct stenosis, having by then been a consultant psychiatrist for some years. The precipitant for ultimate aqueduct failure remains a mystery. The clinical picture in the final phase conformed to that for "normal pressure hydrocephalus", with memory impairment, ataxia and the start of urinary incontinence. However, the clinical picture was far from clear until the final phase. Certainly it was not clear to me or to the colleagues who recognised me as being unwell. In this cautionary tale my medical training did not help me understand my illness and those around me did not perceive its nature either.

In retrospect I can date the first event in the illness as four months before the ultimate surgery last April. The dinner party had started late and the coffee had yet to come when I sank asleep on the accommodating shoulder of the senior lady on my right. It was all laughed off as the result of a long day. Thereafter I struggled on, still thinking that the effect of age on memory was more severe than others had ever revealed. And then I concluded that I was suffering from stress-induced depressive illness, there being some workrelated pressures. How conveniently one finds evidence to support the theory upon which one has settled. My good GP was a fellow traveller with the conclusion, and when I fell asleep at the wheel causing a mercifully slight incident, he supported my notion of treatment with a selective serotonin re-uptake inhibitor (SSRI) and some time off. Even the start of ataxia, with particular difficulty in moving forward out of chairs, I ascribed to an unusual SSRI side-effect. An observant colleague similarly noted occasional report of ataxia as a side effect.

I remain indebted to the team in the psychiatric unit where I became a patient for first seeing the organic nature of my disorder and to the NHS neuro-surgical team who followed through with scan and then with surgery. My clinical colleagues with generous self-critical hindsight recalled after the event that my gait had changed, becoming a little high stepping, that my complaint of hiccoughs had been a pointer away from depression and that my handwriting had charted motor decline. Once the organicity of the case was recognised, I myself should have been wondering where the tumour was. And yet, as my psychiatrist commented, it was almost as though the hydrocephalus had leucotomised' me, sparing me from such appropriate worry.

Anyone in doubt as to the meaning of the term 'busy' might visit a neurosurgical recovery ward at night. My respect for the nurses there endures. There arose for me the question, of course, as to whether I was a doctor or a patient. This was thrown into sharp focus by the disturbance of a fellow patient determined to walk home one night with tubes and all, the whole situation coming close to one in which the duty psychiatrist might be called. The ward team's whispered discussion was amplified by the ancient building and thus I heard that sedation was being considered with an utterly homeopathic dose of major tranquilliser, there being the prospect of a long disturbed night for us all. I decided that I had no advisory function in this unit and that such situations occur in many surgical wards on many nights. My decision to remain passive in my status as a patient was followed by the crisis blowing over somehow.

The shunt insertion was immediately effective. In the following days I could remember my PIN number once again and the phone numbers of old friends. My family recognised me as 'sharp' once again. Psychometric testing produced a flattering result sufficient to support my return to work. I returned on a part-time basis, four months after surgery. However, problems persisted. I was given to short sleeps lasting a few minutes in idle moments. There was no ictal basis for these. Yet they would lead to embarrassment in company, for example in lunch-time meetings. Furthermore I had suffered on two occasions from global 
amnesia lasting 24 hours. The occurrence of a third bout with ataxia after return to work pointed to shunt malfunction and the need for surgical revision.

Shunt revision involved two visits to theatre, some six months after the initial surgery. This was in the hands of a different neurosurgeon. I am now in a convalescent phase once again some three months after the revision. Impairments have receded: ataxia went immediately, exceptional sleep capacity is lessening and short-term memory is now close to normal. However, it is only now that zest and spontaneity are returning and only now that I experience a full emotional range. Immediate as the effects of successful surgery have been, true recovery has been gradual.

I have some observations about the neurosurgical experience. While recovering in my neurosurgical bed and as news came through the headphones of messy injuries in the Gorazde enclave, I reflected that I was fortunate to have the hole in my head made with such skill! Shunts are wonderful for ensuring survival. It came as a surprise that the peritoneal end led to extra girth and a need for trouser enlargement. There is the overall point: that recovery from any form of surgery to the cranium is a gradual matter, more gradual than one might at first think. This point is not universally accepted. The neurosurgical team first involved saw freedom for me to resume work some six or eight weeks after initial surgery.

There is a further point concerning the family's role in such a disorder: I have had to overcome natural independence, learning to rely upon my family not only for valued support but for realistic feedback about my performance.

Name and address supplied 